\title{
BMJ
}

\section{Maternal and neonatal individual risks and benefits associated with caesarean delivery: multicentre prospective study}

\author{
José Villar, senior fellow, ${ }^{1}$ Guillermo Carroli, director, ${ }^{2}$ Nelly Zavaleta, senior researcher, ${ }^{3}$ \\ Allan Donner, professor, ${ }^{4}$ Daniel Wojdyla, statistician, ${ }^{2}$ Anibal Faundes, professor, ${ }^{5}$ Alejandro \\ Velazco, director, ${ }^{6}$ Vicente Bataglia, senior adviser, ${ }^{7}$ Ana Langer, president, ${ }^{8}$ Alberto Narváez, senior \\ researcher, ${ }^{9}$ Eliette Valladares, director, ${ }^{10}$ Archana Shah, scientist, ${ }^{11}$ Liana Campodónico, statistician, ${ }^{2}$ \\ Mariana Romero, senior investigator, ${ }^{12}$ Sofia Reynoso, investigator, ${ }^{13}$ Karla Simônia de Pádua, research \\ coordinator, ${ }^{5}$ Daniel Giordano, computer analyst, ${ }^{2}$ Marius Kublickas, obstetrician-gynaecologist, ${ }^{14}$ \\ Arnaldo Acosta, professor, ${ }^{15}$ for the World Health Organization 2005 Global Survey on Maternal and \\ Perinatal Health Research Group
}

Nuffield Department of Obstetrics and Gynaecology, University of Oxford, Oxford OX3 9DU

${ }^{2}$ Centro Rosarino de Estudios Perinatales (CREP), Rosario, Argentina

${ }^{3}$ Instituto de Investigación Nutricional, Lima, Peru

${ }^{4}$ Department of Epidemiology and Biostatistics, Faculty of Medicine and Dentistry, University of Western Ontario, London, Canada

${ }^{5}$ Centro de Pesquisas em Saúde Reprodutiva de Campinas (Cemicamp), Campinas, SP, Brazil

${ }^{6}$ Hospital Docente Ginecobstétrico "América Arias," La Habana, Cuba

${ }^{7}$ Department of Obstetrics and Gynaecology, Hospital Nacional de Itauguá, Itauguá, Paraguay

${ }^{8}$ EngenderHealth, New York, NY, USA

${ }^{9}$ Fundación Salud, Ambiente y Desarrollo, Quito, Ecuador

${ }^{10}$ Universidad Nacional Autónoma de Nicaragua, León, Nicaragua

${ }^{11}$ Department of Making Pregnancy Safer, World Health Organization, Geneva, Switzerland

${ }^{12}$ CONICET/Centro de Estudios de Estado y Sociedad (CEDES),

Buenos Aires, Argentina

${ }^{13}$ Population Council Regional Office for Latin America and the Caribbean, Mexico City, Mexico

${ }^{14}$ Karolinska Institutet, Stockholm, Sweden

${ }^{15}$ Department of Obstetrics and Gynaecology, Universidad Nacional de Asunción, Asunción, Paraguay

Correspondence to: J Villar jose.villar@obs-gyn.ox.ac.uk

doi:10.1136/bmi.39363.706956.55 in neonatal intensive care and neonatal mortality up to hospital discharge for babies delivered by elective caesarean delivery, but rupturing of membranes may be protective.

Conclusions Caesarean delivery independently reduces overall risk in breech presentations and risk of intrapartum fetal death in cephalic presentations but increases the risk of severe maternal and neonatal morbidity and mortality in cephalic presentations.

\section{INTRODUCTION}

Profound changes have occurred during the past three decades regarding the mode of delivery and perinatal outcomes, ${ }^{1}$ including recent efforts to reduce high rates of caesarean delivery ${ }^{2}$ while at the same time attempting to incorporate women's obstetric preferences. ${ }^{34}$ The increase in rates of caesarean delivery at an institutional level is not associated with any clear overall benefit for the baby or mother but is linked with increased morbidity for both. ${ }^{5}$ There is therefore an urgent need to provide women and care providers with information on the potential individual risk and benefits associated with caesarean delivery.

\section{METHODS}

Participating women were involved in the 2005 WHO global survey on maternal and perinatal health. ${ }^{56}$ The survey explored the relation between rates of caesarean delivery and perinatal outcomes among women delivering in medical institutions from 24 geographic areas in eight randomly selected Latin American countries. A total of 410 institutions were identified, from which 123 were randomly selected for this survey using a multi-stage stratified sampling procedure; three refused to participate.

In each of the selected institutions, we studied all women admitted for delivery during a fixed period, depending on the total annual number of expected deliveries, arbitrarily defined as three months in of all caesarean deliveries for fetal distress. Such

increased risk was not seen for breech presentation. Lack of labour was a risk factor for a stay of seven or more days 
Health facilities identified in 24 geographic units from eight randomly selected Latin American countries $(n=410)$

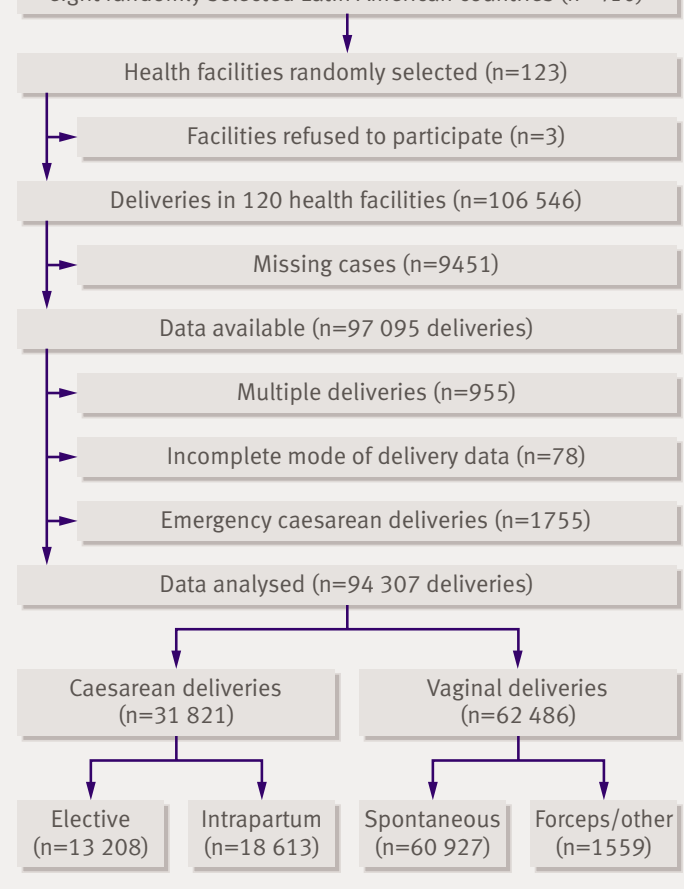

Flow of population through study

institutions with 6000 or fewer deliveries and two months in those with more than 6000. Data collection took place from 1 September 2004 to 30 March 2005.

\section{Data collection}

Trained staff reviewed medical records of all enrolled women within a day after delivery and abstracted information during the period that the woman or newborn remained in the hospital. A nurse or midwife working in the labour or postpartum ward was responsible for data collection on a day to day basis at each institution. A hospital coordinator supervised data collection, resolving, completing, or clarifying unclear medical notes before data entry. Regional coordinators frequently visited participating hospitals and compared a random sample of medical records with their corresponding study forms for evaluation of data quality. ${ }^{56}$

For each woman we collected information on demographic characteristics, risk before conception, events during pregnancy, mode of delivery, and outcomes up to hospital discharge. A manual of operations provided criteria for data abstraction for all staff. ${ }^{7}$ The manual contained definitions of all terms used, synonyms of medical and obstetric terms, and examples of specific questions accompanied by precoded corresponding answers.

\section{Definitions and outcomes}

Caesarean deliveries were classified as elective if the operation was decided by the attending staff before the onset of labour and the woman was referred either from an antenatal clinic or a high risk ward to the delivery unit for caesarean delivery regardless of the diagnosis. Some women started labour before the elective caesarean was performed but were still considered as having elective caesarean delivery if they were delivered by caesarean. In cases of unclear timing of the indication for caesarean, women in whom labour was induced or who had spontaneous labour with anaesthesia during labour were not considered as having an elective caesarean delivery. Intrapartum caesarean delivery was when a caesarean was indicated during labour, whether labour was spontaneous or induced.

We excluded emergency caesarean delivery without labour, which denoted women referred for a caesarean before onset of labour with the diagnosis of acute severe fetal distress, severe vaginal bleeding, uterine rupture, maternal death with a living fetus, eclampsia, or any other diagnosis considered by the attending staff to require emergency elective caesarean delivery.

The perinatal outcomes were fetal death, admission to neonatal intensive care unit for seven or more days, and neonatal mortality up to hospital discharge. "Recent fetal death" included "fresh stillbirths" but excluded all "macerated stillbirths" and all inductions of labour because of fetal death. Severe maternal morbidity was evaluated with proxy events, mostly severe conditions, rather than the clinical diagnosis itself because of problems in standardising definitions. We specifically identified blood transfusion, hysterectomy, maternal admission to an intensive care unit, maternal stay in hospital for over seven days, or maternal death. We constructed a summary index before we analysed the data, taking the value of 1.0 if at least one of the above complications was reported and 0 otherwise, and used this as one of the three primary maternal outcomes. We also studied its five components independently as secondary outcomes. The second primary maternal outcome was postpartum antibiotic treatment, excluding any prophylactic regimen or continuation of prophylactic regimens. It was evaluated separately, as an indicator of maternal postpartum infections. The third maternal outcome was third and fourth degree perineal laceration or postpartum fistulae, or both.

Health institutions were classified as either private or belonging to the public health system or to the social security system (that is, hospitals associated with trade union related systems), as reported by the institutions' authorities. We constructed an index reflecting the complexity of resources available at each institution to summarise its capacity to provide obstetric care in terms of minimum essential or optional services (see www.crep.com.ar). We calculated an overall unweighted score $(0-16)$ for all institutions. ${ }^{5}$ We also recorded the referral status of all women. These three variables were always considered in the adjusted analysis.

All data were continuously entered during the study with a web based system (MedSciNet AB, Stockholm, Sweden) in collaboration with WHO (www.medscinet. com/who). We calculated the survey coverage by 
comparing the number of delivery forms completed during the study period with the total number of deliveries, as independently recorded in the hospital logbook.

Maternal risk factors included variables representing marital status, age ( $\leq 16$ years, $\geq 35$ years), primary education, primigravidity, primiparity, previous caesarean delivery, stillbirth or neonatal death, previous surgery on the uterus or cervix or urinary or gynaecological fistula, and medical condition diagnosed before the current pregnancy or reported as an indication for induction of labour or caesarean delivery. Conditions diagnosed during the current pregnancy included gestational hypertension, pre-eclampsia, eclampsia, vaginal bleeding in the second half of pregnancy, genital warts (condyloma acuminata), suspected impaired fetal growth, or fetal malpresentation at term. As possible confounding factors for inclusion in the regression models we also considered whether the woman was referred, her labour induced, or she received epidural anaesthesia in labour. Gestational age at delivery was always included in the models that were fitted to neonatal outcomes.

We did not adjust for variables considered as process measures such as dystocia, failure to progress, and fetal distress. Previous low and high birth weight, although included as baseline characteristics, were also not considered in the regression models because of a substantial number of missing values.

\section{Analysis}

For each outcome variable of interest, we developed the model using generalised estimating equations, an extension of multiple logistic regression that takes into account clustering effects. ${ }^{89}$ Each model included mode of delivery defined at three levels: vaginal (reference category), elective caesarean delivery, and intrapartum caesarean delivery, as well as those individual level variables listed in table 1 that were significant in univariate analyses $(\mathrm{P}<0.05)$. As mentioned above, gestational age was always included when we considered neonatal outcomes.

Variables that failed to show significance at the $5 \%$ level in the resulting model were then removed one by one until all remaining variables were significant.

Finally, institutional level variables were tested one by one for possible inclusion in the model. These variables were type of facility (three levels: public, social security, private), country (eight levels), and financial incentive for caesarean section (two levels). If any of

Table 1 | Characteristics of the study population according to mode of delivery. Figures are numbers (percentages)

\begin{tabular}{|c|c|c|c|}
\hline & \multirow{2}{*}{$\begin{array}{l}\text { Vaginal delivery } \\
\quad(n=62486)\end{array}$} & \multicolumn{2}{|c|}{ Caesarean delivery } \\
\hline & & Elective ( $n=13$ 208) & Intrapartum $(n=18$ 613) \\
\hline Marital status (single) & $14539(23.4)$ & $2290(17.4)$ & $3338(18.0)$ \\
\hline Maternal age $\leq 16$ years & $2983(4.8)$ & $295(2.2)$ & $790(4.3)$ \\
\hline Maternal age $\geq 35$ years & $5490(8.8)$ & $2281(17.3)$ & 2214 (11.9) \\
\hline$<7$ years of education & $16433(27.6)$ & $2653(21.6)$ & $4292(24.3)$ \\
\hline Primigravida & $21509(34.5)$ & $3518(26.6)$ & $7439(40.0)$ \\
\hline Primiparous & $25730(41.2)$ & $4247(32.2)$ & $9137(49.2)$ \\
\hline \multicolumn{4}{|l|}{ Previous pregnancy } \\
\hline Low birth weight (<2500 g) & $2060(3.8)$ & $641(5.5)$ & $584(3.7)$ \\
\hline High birth weight ( $\geq 4500 \mathrm{~g}$ ) & $243(0.5)$ & $117(1.0)$ & $78(0.5)$ \\
\hline Neonatal death or stillbirth & $618(1.0)$ & $242(1.9)$ & $263(1.4)$ \\
\hline Fistula or uterus/cervix surgery & $2016(3.3)$ & $2738(21.0)$ & $2217(12.0)$ \\
\hline Caesarean delivery & $2084(3.4)$ & $6046(46.1)$ & $4571(24.7)$ \\
\hline \multicolumn{4}{|l|}{ Current pregnancy } \\
\hline Any pathology before index pregnancy* & $2421(3.9)$ & $1180(9.0)$ & $960(5.2)$ \\
\hline Any pathology during current pregnancy† & $18407(29.6)$ & $5264(40.2)$ & $7606(41.2)$ \\
\hline Gestational hypertension, pre-eclampsia, or eclampsia & $3466(5.6)$ & 2475 (18.9) & $2459(13.3)$ \\
\hline Vaginal bleeding in second half of pregnancy & $1145(1.8)$ & $486(3.7)$ & $676(3.7)$ \\
\hline Urinary tract infection & $9071(14.6)$ & $2123(16.2)$ & $2916(15.8)$ \\
\hline Genital warts & $206(0.3)$ & $112(0.9)$ & $127(0.7)$ \\
\hline Suspected intrauterine growth restriction & $641(1.0)$ & $337(2.6)$ & $230(1.3)$ \\
\hline Any other medical condition & $5313(8.6)$ & $1710(13.1)$ & $2179(11.8)$ \\
\hline Rupture of membranes before labour & $7270(11.7)$ & $1097(8.4)$ & $2789(15.1)$ \\
\hline Any antenatal antibiotic treatment & $10898(17.5)$ & $2741(20.9)$ & $3697(20.0)$ \\
\hline Breech or other non-cephalic presentation & $547(0.9)$ & $1874(14.2)$ & $2044(11.0)$ \\
\hline Referred for complication related to pregnancy or delivery & $19615(31.4)$ & $5654(42.8)$ & $7060(37.9)$ \\
\hline Induced labour & $7778(12.5)$ & - & $3222(17.3)$ \\
\hline
\end{tabular}


these variables were significant at the $5 \%$ level, they were retained in the final models. Of main interest in these models was the estimated independent effect on outcomes of each type of caesarean delivery compared with vaginal delivery. The increased risk associated with caesarean delivery was expressed by an adjusted odds ratio with corresponding 95\% confidence interval. For all models fitted, we accounted for clustering effects within facilities using procedure PROC GENMOD in SAS.

The maternal and perinatal health unit of the WHO Department of Reproductive Health and Research and the Centro Rosarino de Estudios Perinatales (CREP), Rosario, Argentina, coordinated the survey. Individual informed consent was not sought (except in Brazil) as we collected data at the institutional level from medical records without identifying the individual women. Informed consent at the institutional level was obtained from the responsible authority.

\section{RESULTS}

The target patient population represented 106546 deliveries reported in hospitals' records, yielding data on 97095 (91\% coverage). We excluded multiple births, emergency caesarean deliveries, and women with incomplete delivery data, which left 94307 deliveries for analysis. Of these, 31821 (33.7\%) were caesarean deliveries: $58.5 \%$ intrapartum and $41.5 \%$ elective. We included all vaginal deliveries in our analysis regardless of the method of delivery-for example, spontaneous or forceps (figure).

For all the primary variables of interest, including caesarean delivery status, birth weight, gestational age, admission to intensive care, and neonatal and maternal mortality, the percentage of missing values was below
$1 \%$. The overall percentage of missing values among other variables exceeded $5 \%$ only for previous infant birth weight, maternal height, and weight.

Most of the hospitals included were of medium complexity; 12 had limited capacity and 11 had complex resources. Twelve hospitals were private, 86 belonged to the public health system, and 22 to the social security system. Among the 12 private institutions, only one had a low complexity index, while three of the 22 social security institutions and 25 of the 86 in the public health group had a low complexity index. In seven of the 12 private institutions $(58 \%)$ there was evidence of economic incentives for caesarean delivery (for instance, hospitals that charged more to patients or senior attending staff received additional income) compared with 45\% (10 hospitals) in social security institutions and only $25 \%$ (22 hospitals) in public hospitals. Specialists or residents in obstetrics and gynaecology performed $99 \%$ of caesarean deliveries and $62 \%$ of vaginal deliveries. Of all anaesthetics during labour or delivery, $95 \%$ were epidural or spinal, $80 \%$ of which were provided by anaesthesiologists.

The most commonly reported indications for elective caesarean delivery were previous caesarean delivery $(44 \%)$, breech presentation $(12 \%)$, pre-eclampsia $(13.5 \%)$, other maternal complications $(12 \%)$, and tubal ligation sterilisation $(7.4 \%)$. For intrapartum caesarean delivery the most common indications were cephalopelvic disproportion (35\%), fetal distress $(26 \%)$, and previous caesarean delivery (32\%).

\section{Maternal outcomes}

Table 1 presents the characteristics of the study population, including demographics and clinical,

Table 2 | Relation between caesarean delivery and maternal morbidity and mortality according to mode of delivery

\begin{tabular}{|c|c|c|c|c|c|}
\hline & \multirow[b]{2}{*}{ No (\%) with vaginal delivery } & \multicolumn{2}{|c|}{ Elective caesarean } & \multicolumn{2}{|c|}{ Intrapartum caesarean } \\
\hline & & No (\%) & Adjusted odds ratio $(95 \% \mathrm{Cl})$ & No (\%) & Adjusted odds ratio $(95 \% \mathrm{Cl})$ \\
\hline \multicolumn{6}{|c|}{ Maternal morbidity and mortality index*: } \\
\hline Overall & $1125 / 62078(1.8)$ & $723 / 13081(5.5)$ & $2.30 \dagger(1.69$ to 3.14$)$ & $742 / 18463(4.0)$ & $1.97 \dagger$ (1.57 to 2.46$)$ \\
\hline Death & $7 / 62455(0.01)$ & $5 / 13198(0.04)$ & $3.38(1.07$ to 10.65$)$ & $11 / 18605(0.06)$ & $5.28(2.05$ to 13.62$)$ \\
\hline Admission to ICU & $339 / 62415(0.54)$ & $359 / 13197(2.72)$ & $3.05 \ddagger(1.44$ to 6.46$)$ & $265 / 18598(1.42)$ & $2.22 \ddagger(1.45$ to 3.40$)$ \\
\hline Blood transfusion & $274 / 62267(0.44)$ & $129 / 13167(0.98)$ & $1.75 \S(1.33$ to 2.30$)$ & $131 / 18522(0.71)$ & $1.39 \S(1.10$ to 1.76$)$ \\
\hline Hysterectomy & $33 / 62230(0.05)$ & 46/13 $109(0.35)$ & $4.57 \uparrow(2.84$ to 7.37$)$ & $54 / 18483(0.29)$ & $4.73 \pi(2.79$ to 8.02$)$ \\
\hline Hospital stay $>7$ days & $550 / 62463(0.88)$ & $336 / 13201(2.55)$ & $2.54^{\star \star}(2.01$ to 3.20$)$ & $406 / 18610(2.18)$ & $2.31^{\star \star}(1.72$ to 3.11$)$ \\
\hline Antibiotic treatment after delivery & $15322 / 62333(24.6)$ & $8177 / 13194(62.0)$ & $4.24 \dagger \dagger(2.78$ to 6.46$)$ & 12 949/18 598 (69.6) & $5.53+\dagger(3.77$ to 8.10$)$ \\
\hline 3rd/4th degree perineal laceration & $477 / 62226(0.77)$ & $23 / 13106(0.18)$ & $0.10 \ddagger \ddagger(0.03$ to 0.30$)$ & $23 / 18479(0.12)$ & $0.07 \ddagger \ddagger$ (0.01 to 0.97$)$ \\
\hline
\end{tabular}

and/or postpartum fistula

$\mathrm{ICU}=$ intensive care unit.

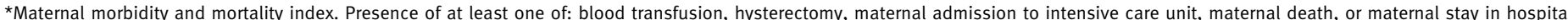
$>7$ days. For maternal death the odds ratios are crude; adjusted ratios cannot be computed because there were too few events.

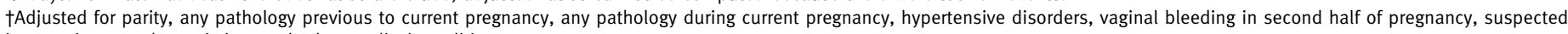
intrauterine growth restriction, and other medical conditions.

$\ddagger$ Adjusted for gravity, any pathology previous to current pregnancy, any pathology during current pregnancy, hypertensive disorders, and other medical conditions.

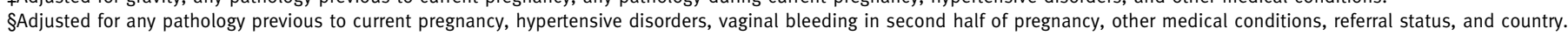

TAdjusted for marital status, maternal age, gravity, any pathology previous to current pregnancy, vaginal bleeding in second half of pregnancy, and referral status.

**Adjusted for parity, caesarean section in previous delivery, any pathology previous to current pregnancy, any pathology during current pregnancy, hypertensive disorders, suspected

intrauterine growth restriction, other medical conditions, fetal presentation, anaesthesia during labour, and country.

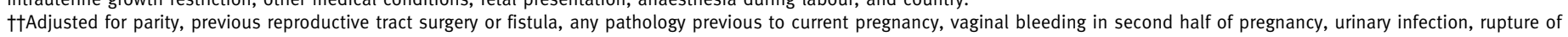
membranes before labour, fetal presentation, and type of onset of labour (induced/not induced).

抽justed for maternal education 
pregnancy, and delivery variables. Compared with women who underwent elective caesarean delivery, those with vaginal deliveries were at higher risk in terms of sociodemographic characteristics (such as single, young age, and low education, gravidity, and primiparity), while the caesarean group had higher risk in terms of women with previous complicated pregnancies or perinatal outcomes, problems related to current pregnancy, and being referred from other institutions for delivery. We observed similar patterns for intrapartum caesarean, although the magnitude of the differences was smaller. Risk factors in women who had an elective caesarean delivery were more prevalent than in women having an intrapartum caesarean (table 1).

In the crude analysis, the maternal morbidity and mortality index in women in the elective caesarean delivery group $(5.5 \%)$ was higher than that in the intrapartum caesarean group $(4.0 \%)$ and vaginal delivery $(1.8 \%)$ groups. The need for antibiotic treatment after delivery was highest in the two caesarean groups, while, as expected, vaginal complications were lowest among them (table 2). Table 2 also presents the adjusted results for the relation between mode of delivery and these indicators of maternal morbidity. A woman with an elective caesarean had an adjusted odds ratio of 2.3 (95\% confidence interval 1.7 to 3.1 ) for having at least one of the events included in the maternal morbidity and mortality index compared with a woman with vaginal delivery. Similarly, a woman with an intrapartum caesarean was more likely to experience maternal morbidity and mortality $(2.0,1.6$ to 2.5$)$ (table 2). We also independently explored each of the five conditions included in this index as secondary outcomes following the same adjustment strategy (table 2). For all conditions, a caesarean delivery (either elective or intrapartum) was associated with a significantly higher risk than a vaginal delivery after adjustment for possible confounding variables. Compared with vaginal deliveries, the risk was three to five times higher for maternal death, four times higher for hysterectomy,

Table 3 | Relation between caesarean delivery (CD) and neonatal outcomes according to fetal presentation at delivery among singletons

Neonatal outcome

No (\%)

Adjusted odds ratio $(95 \% \mathrm{Cl})$

Fetal death

Cephalic presentation*:

\begin{tabular}{lcr}
\hline Vaginal delivery (reference) & $242 / 61870(0.39)$ & 1.00 \\
\hline Elective CD $v$ vaginal delivery & $35 / 11300(0.31)$ & $0.65(0.43$ to 0.98$)$ \\
\hline Intrapartum CD v vaginal delivery & $73 / 16543(0.44)$ & $1.25(0.93$ to 1.67$)$ \\
\hline Breech and other presentationst: & & \\
\hline Vaginal delivery (reference) & $53 / 547(9.69)$ & 1.00 \\
\hline Elective CD $v$ vaginal delivery & $18 / 1874(0.96)$ & $0.27(0.14$ to 0.50$)$ \\
\hline Intrapartum CD $v$ vaginal delivery & $14 / 2043(0.69)$ & $0.20(0.09$ to 0.43$)$ \\
\hline
\end{tabular}

Stay for $\geq 7$ days in neonatal intensive care unit

Cephalic presentation $\ddagger$ :

\begin{tabular}{|c|c|c|}
\hline Vaginal delivery (reference) & $1162 / 61264(1.9)$ & 1.00 \\
\hline Elective CD $v$ vaginal delivery & $562 / 11239(5.0)$ & 2.11 (1.75 to 2.55$)$ \\
\hline Intrapartum CD v vaginal delivery & $568 / 16428(3.5)$ & 1.93 (1.63 to 2.29$)$ \\
\hline \multicolumn{3}{|l|}{ Breech and other presentations§: } \\
\hline Vaginal delivery (reference) & $55 / 422(13.0)$ & 1.00 \\
\hline Elective $C D v$ vaginal delivery & $126 / 1845(6.8)$ & $1.28(0.76$ to 2.14$)$ \\
\hline Intrapartum CD v vaginal delivery & $141 / 2014(7.0)$ & 1.31 (0.79 to 2.18$)$ \\
\hline \multicolumn{3}{|c|}{ Neonatal mortality up to hospital discharge } \\
\hline \multicolumn{3}{|l|}{ Cephalic presentationף: } \\
\hline Vaginal delivery (reference) & $231 / 61299(0.38)$ & 1.00 \\
\hline Elective CD $v$ vaginal delivery & $87 / 11237(0.77)$ & 1.66 (1.26 to 2.20$)$ \\
\hline Intrapartum CD v vaginal delivery & $107 / 16434(0.65)$ & 1.99 (1.51 to 2.63$)$ \\
\hline \multicolumn{3}{|l|}{ Breech and other presentations ${ }^{\star \star}$ : } \\
\hline Vaginal delivery (reference) & $36 / 421(8.55)$ & 1.00 \\
\hline Elective $C D v$ vaginal delivery & $33 / 1846(1.79)$ & $0.69(0.35$ to 1.34$)$ \\
\hline Intrapartum CD v vaginal delivery & $33 / 2021(1.63)$ & $0.55(0.30$ to 1.02$)$ \\
\hline
\end{tabular}

${ }^{*}$ Odds ratios adjusted for gestational age, maternal age, education, previous stillbirth or neonatal death, vaginal bleeding in second half of pregnancy, other medical conditions, type of onset of labour (induced/not induced), and country.

†Odds ratios adjusted for gestational age and type of onset of labour (induced/not induced).

fOdds ratios adjusted for gestational age, maternal age, caesarean section in previous delivery, any pathology during current pregnancy, hypertensive disorders, suspected intrauterine growth restriction, other medical conditions, rupture of membranes before labour, and country.

$\S 0 d d s$ ratios adjusted for gestational age, any pathology previous to current pregnancy, and country.

TOdds ratios adjusted for gestational age, hypertensive disorders, any anaesthesia during labour, and type of facility.

$\star \star$ Odds ratios adjusted for gestational age. 
and twice as high for being admitted to intensive care and hospital stay more than seven days (table 2).

Furthermore, the odds ratio for antibiotic treatment after delivery in women who underwent a caesarean (elective or intrapartum) was four to five times that for women with vaginal delivery (both significant). As expected, both elective and intrapartum caesarean delivery had a large protective effect on the incidence of postpartum fistula or third or fourth degree perineal laceration, or both. The odds ratio was 0.10 (0.03 to 0.30 ) for elective caesarean and 0.07 (0.01 to 0.97$)$ for intrapartum caesarean (table 2).

\section{Fetal and neonatal outcomes}

In the crude analysis for fetal and neonatal outcomes, the highest rates of neonatal morbidity and mortality were seen in the elective caesarean group, but fetal death rates were similar in the three groups (table 3 ). The rates of preterm delivery were $7 \%$ for vaginal deliveries, $12 \%$ for elective caesarean, and $9 \%$ for intrapartum caesarean. We then studied the association between the mode of delivery and the three primary fetal and neonatal outcomes, stratifying the analysis for fetal presentation at delivery and adjusting for possible confounding variables and gestational age at delivery (table 3). With cephalic presentation, elective caesarean was associated with a marginally significant reduction in the risk of fetal death $(0.7,0.4$ to 1.0$)$ compared with vaginal delivery, but this effect was not observed for intrapartum caesarean. The 35 fetal deaths in the elective caesarean group were similarly distributed among women with or without any labour before the caesarean. In these 35 women, the indication for caesarean was previous caesarean in 10, pre-eclampsia in nine, and fetal indications in 11. With breech presentation, however, both types of caesarean were associated with a large reduction in risk of intrapartum fetal death compared with vaginal delivery (table 3 ).

We also explored the relation between caesarean delivery and stay in the neonatal intensive care unit for seven or more days (as proxy for severe neonatal

Table $4 \mid$ Relation between caesarean delivery (CD) and neonatal outcomes among singletons with cephalic presentation excluding all cases with caesarean delivery indicated because of fetal distress

\begin{tabular}{lcc}
$\begin{array}{l}\text { Neonatal outcome } \\
\text { Stay for } \geq 7 \text { days in neonatal intensive care unit* }\end{array}$ & No (\%) & $\begin{array}{c}\text { Adjusted odds ratio } \\
(95 \% \mathrm{Cl})\end{array}$ \\
\hline Vaginal delivery (reference) & $1162 / 61264(1.9)$ & 1.00 \\
\hline Elective CD $v$ vaginal delivery & $528 / 10713(4.9)$ & 2.10 (1.75 to 2.53) \\
\hline Intrapartum CD $v$ vaginal delivery & $389 / 11881(3.3)$ & 1.76 (1.47 to 2.10) \\
\hline Neonatal mortality up to hospital discharge & & 1.00 \\
\hline Vaginal delivery (reference) & $231 / 61299(0.38)$ & 1.76 (1.33 to 2.32) \\
\hline Elective CD $v$ vaginal delivery & $83 / 10711(0.77)$ & 1.29 (0.94 to 1.78$)$ \\
\hline Intrapartum CD $v$ vaginal delivery & $61 / 11884(0.51)$ &
\end{tabular}

*Odds ratios adjusted for gestational age, maternal age, caesarean section in previous delivery, hypertensive disorders, suspected intrauterine growth restriction, other medical conditions, rupture of membranes before labour, country.

†Odds ratios adjusted for gestational age. morbidity). With cephalic presentation, after adjustment for possible confounding variables and gestational age, both elective and intrapartum caesarean delivery were associated with almost double the risk of admission to a neonatal intensive care unit for seven or more days (table 4). With breech presentation, however, elective and intrapartum caesarean delivery were not independently associated with significantly higher risk (table 3).

We explored similar relations for neonatal mortality up to hospital discharge, again according to fetal presentation and with adjustment for several possible confounders and gestational age. With cephalic presentation, intrapartum caesarean was associated with twice the risk of neonatal death. A similar but smaller effect $(1.7,1.3$ to 2.2$)$ was observed for elective caesarean delivery. With breech presentation, however, both types of caesarean were associated with lower neonatal mortality up to hospital discharge, although the odds ratios were not significant (table 3).

Despite all these extensive statistical adjustments, the observed effect of caesarean delivery on neonatal outcome with cephalic presentation might be confounded by the indication for the caesarean delivery, particularly for intrapartum caesarean delivery. We therefore conducted a sensitivity analysis excluding all caesareans with the indication of "intrapartum fetal distress" and again adjusted for gestational age and other confounding variables. The negative effect of caesarean delivery on neonatal morbidity with cephalic presentation remained after we excluded all cases of "fetal distress" as the indication for caesarean. For neonatal mortality up to hospital discharge, however, the association with intrapartum caesarean delivery was no longer significant (table 4). Exclusion from the vaginal delivery group of all inductions of labour associated with fetal distress did not change these results.

We further explored the lack of labour before surgery as a possible mechanism for the consistent negative effect of elective caesarean delivery. For this purpose, we studied only women who had an indication for elective caesarean delivery but stratified them according to whether or not they had spontaneous initiation of labour before the caesarean was actually performed and compared them with those who did not have spontaneous labour. Among the 11229 women with elective caesarean delivery and fetuses in cephalic presentation for whom we have information about initiation of labour, 1652 women (15.0\%) experienced spontaneous initiation of labour before the surgery. We compared these two subgroups with women who had spontaneous initiation of labour and vaginal delivery in cephalic presentation (as the reference group) adjusted, as before, for gestational age at delivery and the identified possible confounding variables. We restricted this analysis to those in cephalic presentation because of the protective effect of caesarean delivery for neonatal outcomes among breech presentations (table 5). 
Elective caesarean delivery without labour was associated with an increased risk for admission to a neonatal intensive care unit for seven or more days (adjusted odds ratio 2.2, 1.8 to 2.7) and for neonatal mortality $(1.8,1.4$ to 2.3$)$, both higher than the corresponding observed increased risk for elective caesarean delivery with labour before surgery (odds ratio $1.4,0.6$ to 3.4 ) for neonatal mortality and for admission to neonatal intensive care (adjusted odds ratio 1.4, 1.0 to 2.0) (table 5). These odds ratios were adjusted for possible confounding variables and gestational age at delivery. Exclusion of caesarean deliveries associated with fetal distress, as in the previous analysis, did not modify these associations. The adjusted odds ratio for elective caesarean with labour was significantly lower for admission to a neonatal intensive care unit for seven or more days than the adjusted odds ratio for caesarean delivery but no labour before surgery $(\mathrm{P}<0.05)$.

Furthermore, we stratified women with spontaneous labour before their elective caesarean according to whether or not their membranes were ruptured before labour and focused on admission to neonatal intensive care for seven or more days as the primary neonatal outcome because there were too few neonatal deaths in these subgroups. The risk of admission was still higher for those with spontaneous labour but without rupture of membranes $(1.5,1.1$ to 2.2$)$ but was no longer present with both spontaneous labour and rupture of membranes $(0.9,0.3$ to 3.1$)$ before an elective caesarean.

\section{Intended method of delivery}

All previous analyses were based on the concept of "actual" mode of delivery. A complementary evaluation included the concept of "intended" mode of delivery-that is, women who may have had the "choice" (clinically or circumstantially) of attempting a vaginal delivery compared with women who intended or needed to have an elective caesarean. To explore this alternative, we compared all women with elective (intended) caesareans with all women who "intended" a vaginal delivery, even if some of them eventually delivered by intrapartum caesarean.

Table 5 | Relation between elective caesarean delivery (CD) and neonatal outcomes among singletons with cephalic presentation according to initiation of labour before elective caesarean

\begin{tabular}{|c|c|c|}
\hline Neonatal outcome & No (\%) & Adjusted odds ratio $(95 \% \mathrm{Cl})$ \\
\hline \multicolumn{3}{|l|}{ Stay for $\geq 7$ days in neonatal intensive care unit* } \\
\hline Spontaneous onset/vaginal delivery (reference) & $1035 / 53361$ (1.9) & 1.00 \\
\hline Spontaneous onset/elective CD & 44/1652 (2.7) & $1.43(1.01$ to 2.01$) \dagger$ \\
\hline No labour/elective CD & $516 / 9577(5.4)$ & $2.22(1.81$ to 2.74$) \dagger$ \\
\hline \multicolumn{3}{|l|}{ Neonatal mortality up to hospital discharge } \\
\hline Spontaneous onset/vaginal delivery (reference) & $193 / 53379(0.36)$ & 1.00 \\
\hline Spontaneous onset/elective CD & $10 / 1651(0.61)$ & 1.41 (0.59 to 3.37$)$ \\
\hline No labour/elective CD & $77 / 9576(0.80)$ & 1.82 (1.43 to 2.32$)$ \\
\hline \multicolumn{3}{|c|}{$\begin{array}{l}\text { *Odd ratios adjusted for gestational age, maternal age, caesarean section in previous pregnancy, hypertensive } \\
\text { disorders, suspected intrauterine growth restriction, other medical conditions, rupture of membranes before } \\
\text { labour, and type of facility. } \\
\dagger \text { Comparison between "spontaneous onset, elective CD" and "no labour, elective CD": odds ratio 1.6, } 1.1 \text { to 2.2, } \\
\text { P } 0.05 \text {. } \\
\ddagger 0 \text { dds ratios adjusted for gestational age. }\end{array}$} \\
\hline
\end{tabular}

Women with intended caesarean remained at higher risk for morbidity and mortality as well as for antibiotic treatment after delivery compared with women with intended vaginal delivery $(1.7,1.3$ to 2.2 , for maternal morbidity index and 2.8, 2.0 to 4.0, for antibiotic treatment after delivery). We observed a similar pattern for the individual components of the index as presented in table 2. For the fetal and neonatal outcomes with cephalic presentations, the patterns observed in the previous analysis also remained: for intended caesarean compared with intended vaginal delivery, after adjusting for possible confounding variables we observed a reduction in risk of fetal death $(0.6,0.4$ to $0.9)$ but an increased risk for admission to neonatal intensive care for seven or more days $(1.6,1.4$ to 1.8$)$ and for neonatal mortality up to hospital discharge (1.3, 1.0 to 1.8). There was no differential risk for intended caesarean delivery versus intended vaginal delivery for fetuses in breech presentation.

\section{DISCUSSION}

Women undergoing caesarean deliveries, either intrapartum or elective, independent of demographic and clinical characteristics or experience of pregnancy had double the risk for severe maternal morbidity and mortality (including death, hysterectomy, blood transfusion, and admission to intensive care) and up to five times the risk of a postpartum infection compared with women undergoing vaginal delivery. Though caesarean delivery carries almost no risk of severe vaginal complications and a slightly reduced risk of intrapartum fetal death, in cephalic presentation it is significantly associated with an increased risk of severe neonatal morbidity and mortality, independent of fetal distress and gestational age. With breech presentation, caesarean delivery substantially reduces the risk to the baby with cephalic presentation. Labour and rupture of membranes before spontaneous labour before an elective caesarean delivery also reduced the risk associated with this mode of delivery.

\section{Limitations of our study}

There were inevitable difficulties in working with a large number of health institutions, staff, medical protocols, and records formats, as well as a fairly limited standardisation of diagnoses and indications for caesarean delivery, which could have produced some misclassification between elective and intrapartum caesarean. To minimise these, we restricted outcomes to severe morbidity and mortality and abstracted data immediately after delivery with the opportunity to review unclear or incomplete records directly with the attending medical staff. Nevertheless, a few inconsistencies remained in the dataset, such as women reported as having fistula or perineal laceration after a caesarean delivery, as well as some conflicts in the diagnosis of antepartum and intrapartum fetal death. We therefore recommend caution in the interpretation of the results concerning fetal death.

We focused on hospitals with high rates of caesarean delivery (median 34\%) in the context of a wide range of 
care providers, antenatal care systems, and sociocultural circumstances within a particular geographic region. Overall perinatal mortality was low, similar to that from developed countries. Therefore our observations may not be relevant to institutions with lower rates of caesarean sections or to other regions of the world.

Finally, we have considered maternal morbidity and mortality only up to the time of women's hospital discharge. Some women could have had complications after discharge. This could be relevant among women after vaginal deliveries as they tend to be discharged earlier, possibly leading to an exaggeration of the risks after caesarean.

Although we adjusted for several potential confounding variables, it is possible that other factors related to the indication for caesarean, for which we did not have data, or the lack of adjustment for variables reflecting management style or subjective diagnoses - for example, failure to progress or fetal distress - could have biased the magnitude of the observed negative association. This is an important concern in studies of this nature. On the one hand, women undergoing caesarean delivery had a higher clinical risk for negative outcomes of pregnancy, but on the other hand they had lower risk of pregnancy based on their sociodemographic characteristics. It could therefore be argued that considering the clinical risk in the two caesarean groups, this was the best delivery strategy and the observed negative neonatal outcomes would have been more prevalent had the caesarean delivery not been performed (indication bias).

Nevertheless, we believe that our extensive statistical adjustments and the consistency of results for the two types of caesarean delivery preclude such a major shift in the direction of the observed effect. A comparison of crude and adjusted odds ratios also showed that while adjustment was effective in reducing the magnitude of the crude association it remained significant even for rare events such as death. We also consider that it is unlikely that $34 \%$ observed in this study population, similar to the proportion seen in other well educated populations ${ }^{10}$ will have medical indications for a caesarean. In addition, our large sample allowed us to exclude emergency caesarean deliveries and perform sensitivity analyses excluding cases of "fetal distress" as an indication for delivery. Results remained mostly unchanged. Moreover, similar data have recently been reported from a low risk primiparous population in Massachusetts, United States, at a similar time period. ${ }^{11}$ In the US report women with "intended" caesarean delivery had double the risk for maternal readmission to hospital during the first 30 days after delivery (mostly because of wound complications and infections) than women with "intended" vaginal delivery. The magnitude of this effect is similar to that observed by us for early severe maternal morbidity in a different population and under different clinical conditions.

We confirmed the protective effect of caesarean delivery with breech presentation, similar to that seen in a multicentre randomised trial. ${ }^{12}$ It is clear that these babies, regardless of gestational age, should be delivered by planned caesarean. Considering that breech presentations at term represent close to $4 \%$ of all pregnancies, an active strategy using, for example, external cephalic version could help to reduce the rate of primary caesarean deliveries.

We observed an increase in neonatal morbidity and mortality associated with both elective and intrapartum caesarean delivery with cephalic presentation, which remained significant after adjustment for several confounding variables including previous caesarean delivery and gestational age at delivery. Sensitivity analyses excluding cases with "fetal distress" also did not change the results. Indeed the magnitude of the effect observed was almost the same as the recently reported results from the US. In the US study, primary caesarean deliveries with "no indicated risk" were significantly associated with neonatal mortality (2.0, 1.6 to 2.6), thus supporting the concept that caesarean delivery has a true biological effect. ${ }^{13}$

Which factors can explain such a negative effect with cephalic presentation? By reducing fetal death (even slightly), caesarean delivery might increase the pool of sick babies, thus transferring deaths from the fetal to the neonatal period. Furthermore, in our population, there was a relatively low rate of forceps deliveries. A proportion of fetuses with intrapartum distress during the second stage of labour might have been delivered by caesarean rather than vaginally, potentially increasing the number of neonatal complications in the caesarean delivery group. Nevertheless, exclusion of all caesareans associated with fetal distress did not change the observed increased risk.

Elective caesarean delivery could increase neonatal morbidity and mortality because lack of labour affects the physiological process for initiation of respiration. Caesarean delivery is known to be associated with respiratory distress syndrome and transient tachypnoea possibly mediated by the lower release of catecholamine and prostaglandins, as well as the lack of the mechanical compression of the lungs during labour needed to facilitate postnatal lung adaptation. The reduced risk we have described among elective caesarean deliveries in women who underwent labour and ruptured their membranes before surgery tends to support this suggestion.

\section{Implications of results}

Three main paths could lead to the decision to perform a primary caesarean delivery in cephalic presentation. The first consists of severe emergency complications for which the operation is mandatory. As a second path, caesarean delivery might be used to prevent possible perinatal complications based on intrapartum screening methods, usually electronic fetal monitoring or some clinical parameters. These methods are known to have high false positive rates. We believe that far more research must be conducted into new techniques for intrapartum fetal monitoring based on present day technology. Unfortunately, recent attempts to reduce 


\section{WHAT IS ALREADY KNOWN ON THIS TOPIC}

Rates of caesarean delivery have increased dramatically

Caesarean delivery increases the risk of maternal morbidity but the risks and benefits to the baby are still debated

\section{WHAT THIS STUDY ADDS}

In a range of practice settings and outcomes, non-

emergency caesarean delivery increased morbidity and

mortality among cephalic presentations

Delivery by caesarean is recommended for breech

presentations, regardless of the gestational age

Incidence of fetal death and vaginal complications may be reduced by caesarean section

the numbers of caesareans by adding fetal pulse oximetry have not been successful. ${ }^{14}$ Finally, some caesareans are related to a range of social-culturaleconomical-legal factors, including women's demand, ${ }^{15}$ without a clear clinical indication. Our data strongly suggest that with cephalic presentation the surgical procedure itself is independently associated with increased maternal and neonatal morbidity and mortality in a wide range of medical practices and sociocultural settings. On the positive side, there is a clear short term protective effect for vaginal complications that could eventually reduce long term consequences, although this remains to be confirmed. ${ }^{16-18}$

Our results can be used by providers of obstetric care and women and their families during the decision making process regarding mode of delivery in the absence of a life threatening clinical situation. There is a clear demand for such information, ${ }^{19}$ and guidance is expected from medical personnel. ${ }^{20}$ Interpreted in conjunction with our previous report, which focused on factors at the institutional level, ${ }^{5}$ we conclude that any net benefit from the liberal use of caesarean delivery on maternal and neonatal outcomes, at the institutional or individual level, remains to be demonstrated, with the exception of fewer severe vaginal complications after delivery and better fetal outcomes among breech presentations. Caesarean delivery also costs considerably more. ${ }^{11}$ The need for a randomised controlled trial comparing planned caesarean delivery for all women versus vaginal delivery ${ }^{21}$ remains unclear based on our results from the analysis of "intended" mode of delivery.

We thank P Bergsjö, E O Akande, and D Oluwole, who participated during the preparatory phase of the survey and provided advice and support during its implementation; S Marthinsson for technical support to the on-line data entry system; M E Stanton and P F A Van Look for continuous support for the survey; M Taljaard for her statistical comments on an advanced version of the manuscript; and I MacKenzie for his ideas for the intended method of delivery analysis.

Steering committee: A Faundes (chairman), L S Bakketeig, E O Akande, A Kosia, A Langer, G Carroli, P Lumbiganon, D Oluwole, M Lydon-Rochelle, ex officio J Villar, A Shah, L Campodónico (regional data manager), D Giordano, J Villar, A Shah.

Data analysis subcommittee: D Wojdyla, J Villar, A Donner, M Taljaard, L Campodónico, F Burgueño, R Zanello.

\section{Country collaborators}

Argentina: M Romero, M Molinas, B Petz; R Votta, R Winograd, S Bulacio (Hospital General de Agudos “Cosme Argerich”); P Saposnik, N J Bruno, L Acuña, M Pared, G Perez Giambriani (Hospital General de Agudos "José María Penna”); P Justich, R Luca, S Mazzeo, M Marinelli (Hospital General de Agudos Donación F Santojanni); J D Argento, L Flores, M V Secondi (Hospital Materno Infantil Ramón Sarda); J Falcón, A Brondolo, G Musante (Clínica y Maternidad Suizo Argentina); A Lambierto, J Pascual, H Bergondo, L Bouyssounadea Agüero (Sanatorio Otamendi); H Marchitelli, L Otaño, M Sebastiani, J Ceriani Cernadas, J Saadi (Hospital Italiano); R Rizzi; M E Jofre, D Cerda, MF Rizzi (Hospital Universitario de Maternidad y Neonatología); H E Bolatti, L M Ramallo, J Mainguyague, F Crespo Roca (Hospital Materno Neonatal); M J Figueroa, J M Olmas, E Villar, J Oviedo, Z Maldonado, V González, M I Viale, P Feier, L Rodriguez, F Rolon, C Barbieri, M García Salguero (Hospital Materno Provincial); F Andion, P Panzeri (Hospital Misericordia); J Nores Fierro, M Jofre, D Santoni, I Maggi, F Bazan Flett, S Aodassio, L Ret Davalos, G Goldsmorthi (Sanatorio Allende Privado Cordoba); R T Garcia; S M Adla, A Gomel, S S Cataldi, J Mema, R Segura, M Chandia, S Guzman, S Montecino, V Villanueva, S Ciancia, C Pepino, M A Rolon, M C Uria, A Moreno, A B Pedron (Hospital Area Programa "Dr Francisco López Lima"); S S Parsons, MI Giraudo, N N Rebay, NB Menna, J Cortés Alvarado, C M Gonzalez (Hospital Area Programa "Dr Ramón Carrillo")

Brazil: A Faúndes, K S de Pádua, M J D Osis, A H Barbosa, O B Moraes Filho, J Nunes, C Barros, V Zotareli (Centro de Pesquisa em Saúde Reprodutiva de Campinas, Cemicamp); L D C da Motta, J P da Silva Netto, A H Barbosa, H M Nishi, C A N Neves, R C Viana, J Alves Neto, A S Carvalhinho Neto, C K Hueb, C Mariani Neto, E Santana, M Ymayo, R Abreu Filho, R A A Prado, C F G Gonçalves, R C V Valverde, E Araújo Filho, A I de Souza, O B Moraes Filho; A R Batista, B P P Antunes, D Gomes, M Vieira, R G Vasconcelos, J P da Silva Netto, A A Rezende, C A A Rocha, C M da Silva, G Marcelo, M Arcanjo, L C Muniz, L Mondes, M S Barros, E T Rodrigues, R C Viana, M B Dal Cal, M R Ramalho, R M Teixeira, E M Martin, D F Noventa, A L F Gonçalves, S M Nascimento, A C Oliveira, M C Bernardo, F T Santos, C S Moreno, A Vidal, D A M de Souza, G A C Ângelo, R L Garcia, R Carrasco, R lannitta, L C Motta, L F Ripino, A G R Berrocoso, J L Caneppele, R P de Souza, A A de Oliveira, P C Gonçalves, G B dos Santos, A K Malaquias, F R B Silva, L S Viegas, M I M da Silva, R H M Kubota, V D Fogaça, D B B Ziziotti, R Buonacorso, K C G da Silva, V P da Silva, C F G Gonçalves, M D Silva, M F S Araújo, T L C Fernandes, R C V Valverde, C F V dos Santos, A C F de Figueiredo, A F F de Albuquerque, I F de Melo, R L C de Lima, G de Moraes, M C Beuquior, R Alves.

Cuba: A Velasco Boza, U Farnot, J Martinez, A Rguez Cárdenas (Hospital America Arias); A Ortusa Chirino (Hospital Ramon Gonzalez); D Dueñas (Hospital Materno 10 de Octubre); C R Fuentes Paisán (Hospital Enrique Cabrera); V Hojoy Rivalta (Hospital Eusebio Hernandez); I Barrio Rivero (Hospital Materno Guanabacoa); C M Corral Marzo, I Díaz García (Maternidad Norte Tamra Bunke); Y Fayat Saeta (Hospital General Santiago); M Vensan Massó (Maternidad Sur Mariana Grajales); B Filgueira Argote (Hospital Orlando Pantoja Tamayo); L Vázquez Fernández (Hospital Palma Soariano); L Munder Benítez (Hospital General San Luis); E Verdecia; J P Martínez Silva (Hospita Vladimir I Lenin); J Martínez Rodriguez (Maternidad Infantil Banes); L Vega Estévez (Hospital Martires de Mayari); E Abad Brocard (Hospital Guillermo Luis); J Hiraldo Martínez (Hospital Juan Paz Camejo).

Ecuador: R Cantos; I Cantos, A Quevedo, K Márquez, J González, N Rosales (M E Sotomayor); M Falcones (Hospital Guayaquil); R Cordero (Hospital Mat Guasmo); I Guerra (Hospital Mariana de J); M Palma (Hospital Libertad); H Orrala (Hospital Salinas); C Velasco (Hospital Milagro); F Barba; N Carrión (Hospital Isidro Ayora); N Ochoa (Hospital Isidro Ayora); P Ordóñez (Hospital Civil de Macara); L Astudillo (Hospital Vilcabamba); S Hidalgo (Hospital IESS y Clínica S José); P Jácome; A Villacrés, F Reyes, P Basantes (Hospital Mat Isidro Ayora); E Amores (Hospital Enrique Garcés); N Amores, M Duran, C Hinojosa, R Villalba (Hospital Enrique Garcés); F Delgado, A Estrada, A Meza (Hospital Pablo A Suárez); N Laspina (Hospital Patronato San José); V Dávalos (Hospital Del IESS); M Cortés (Hospital Del IESS); P Narváez, H Pozo (Funsad); A Narváez (MSP); B Vera (Funsad); N Pozo (MSP).

Mexico: E Becerra Muñoz, P Cruz Garcia, M G Santiago Ramos, M G Lizaola Díaz (Hospital Materno Infantil de Inguarán); C Vargas Garcia, M López Maldonado, A González Galavíz (Hospital de la Asoc Hispano Mexicana CIMlgen Tláhuac); J L Garcia Benavides, A Gómez Mendieta, L M Alvarado Bárcenas, M L León Hernández, C Espinoza De los Monteros y Guzmán, M Ruíz Muñóz (Hospital de la Mujer); 0 A Martínez Rodríguez, I Peralta García, S Hernández Porras, E Nava Granados, P Pineda López, J Pozos Garcia (Hospital La Raza IMSS); 
J C Izquierdo Puente, M Moreno Camacho, R Sauer Ramírez, G Jiméénez Solís, J A Ayala Méndez, A L Lara González, M Villa Guerrero, R M Arce Herrera (Hospital Dr Luis Castelazo Ayala); M T Martínez Meza, M Díaz Sánchez, A F Vargas, J A Martínez Escobar, P Pérez Bailón, E López González, O D Balvanera Ortiz, L del Carmen Alvarado Vilchis, M T Valencia Villalpando, M C Rodríguez Sánchez, J A Vázquez Garcia, G Tinoco Jaramillo, A A Santos Carrillo, R M Toledano Cuevas, R J Jasso Ramos, J Ruíz Cristóbal, G Torres Palomino, É E Ochoa Ruíz, L Pérez Rodríguez, R Quizaman Martínez, O Ramírez Garcia (Hospital del Paso y Troncoso); (Guanajuato) E Lowenberg Fabela, E Lowenberg Bolaños, E Mares Martínez (Hospital Tehuantepec); I J Rios, A Patiño Ramirez, A Meneses Rivas, C D Tafoya Zavala, J I Durán Bañuelos, A Vega Negrete, S Vázquez González, V H Rocha Ortiz (Hospital General de Zona No 2 Irapuato IMSS); R M Zavala Gónzález, D Flores Hernández, J Manríquez Mejía, Y Espinoza Balcazar, R Rivera Colín, C Guadiana Pantoja, R López Aguilera, R Valencia Escogido, I Torres Aguirre, G Jiménez Cervantes, E Badillo Garza, M de los Angeles Rivera Rayón, M P Almaguer Ibarra, D A Jaime Trujillo, JL Arteaga Domínguez, M Tinajero Ramítez, M Del Rosario Pérez Roque, R Herrera Patiño (Hospital General de Zona No 4 Celaya); L M Vera Candanedo, MA Ramírez López (Hospital General de Zona No 3 Salamanca) A Estrada Escalante, L Fernando Huerta, F J Avelar Ramírez, V Godínez (Hospital de Gineco Pediatría No 48); M de Gracia Roque Díaz de León, R Garcia Araujo, J R Torrero Solorio (Hospital General de Irapuato); T Puga Rodríguez, JA Vázquez Rojas, M de la Luz Ruíz Jaramillo (Hospital General de León); M M Moraila Ochoa, J de Jesús Rivera Huerta, Enf Liliana Herrera Santana, José Alfredo López, Enf Norma Leticia Morales Serrano, Enf Rosa Elena Rodríguez Sahui (Hospital General del Estado); F Castillo Menchaca, L Pérez Perales, IL Barrera Azuara, M A Robles Mejia (Hospital General de Tampico); V Garcia Fuentes, G García Salinas, R I Ayala Leal, E Romero Alvarez, O Sepúlveda Ruvalcaba, N L Paulín González, L Munguía Rodríguez, L Ramírez Arreola, J A Cerda López, W C Martínez Brambrilia (Hospital General de Matamoros); J G Saucedo Lerma, J A Ramos, M A Sánchez, J A Ramos Flores, J M Compean González, E Ramírez Elías, N Y Montoya Hernández, C O Sosa González, G D Maciel Palos, P Y Cristobal Coronado, E Cavazos Moreno, L De Souza Pagocauco, Y L Cortazo Gómez, L Espino Vázquez, RA Ruíz López, H F Gómez Estrada, J J Flores Pulido, B C Rodríguez López, N Hernández Sánchez (Hospital General de Zona No 15); P Cuauhtémoc Cruz Gómez, C Sánchez Toledo, A M Conti Briceño, M A Alvarez Raso, M A Avila Escobar, A Colas, L F Cuevas Lezama, O Hernández Robles, A Ibarra Rodríguez, R Moctezuma Rodríguez, O M Torres, J M Robles Reyes, E Vázquez Mora, E Bouchan Rivera, F J Camacho González, F E Escobar Loe, M García Guzmán, O A García Ruíz, M L Guemez Rivera, K Guevara González, A L Medina Zaragoza, E I Pérez Cástro, B W Ruíz Hernández (Hospital General Regional No 6); C R Aguirre, J Gutiérrez González, J S Rodríguez Córdoba, C Rangel Aranda, G Bennet Lara, A Velázquez Escamilla, A Bernal Salazar, S Pastor Chao, J Murillo Cruz, N López Garza, F Baeza Estrella, JC Decilos García, E Caro Rojas, L López Hernández, F J Lara Vázquez (Hospital General de Zona № 3); J L Landero Reyes, G Juárez Jiménez, S Gallardo Cruz, C Medeles Gómez, J Pérez Castillo, D E Hernández Caballero, M A Diego Andrade, J M Zamora Cabrera (Hospital General de Zona No 11); U Pizarro Esquivel, G Martínez del Bosque, L R Herrera Pérez, O Pérez Covian, S Márquez de los Santos, T A Rodríguez Parra, G Rodríguez Garza, M S Cabañas Rodríguez, I A Rodríguez García, L Hernández Hernández, A R Gómez González, D González Cruz, M I Castillo Walle, U E Martínez Eufragio, E M Sánchez Mendoza, S Vázquez López, S Castillo Martínez, A Ruíz Lemus, J A Elizalde Barrera, B Márquez Carranza, M Chávez Velásquez (Hospital General de Zona No 13); J Azuara Rebordea, F G Galván González, A Navarrete Escobar, A M Hernández Sánchez, R A Aguirre Ledesma, V Turrubiates Conde; R Rodríguez González, M Díaz Córdoba,

I Aquino Cerero, C Mártinez Moreno, R Rodríguez Martínez, S Del R Reynoso Delgado.

Nicaragua: J Flores Martinez, M Hernandez Muñoz, I J Almendarez (Hospital Fernando Velez Paiz); D Arguello Pallais, V Mantilla, DA Pallais, C Amuretti (Hospital de la Mujer Bertha Calderon Roque); A Villanueva, C Cerrato, J Bonilla Lao (Hospital Aleman Nicaraguense); C E Nicaragua Darce, C E Nicaragua Darce (Centro De Salud Julio Buitrago Urroz); S Benavidez Lanuza, S Benavidez Lanuza (Centro De Salud Yolanda Mayorga); M E Miranda Molina F Guevara Garcia (Hospital Militar Alexandro Davila Bolaños); A Gonazales Rojas (Hospital Escuela Oscar Danilo Rosales Arguello); R Olivas Montiel J Canales (data collector) (Hospital Luis Felipe Moncada).

Paraguay: C V Urdapilleta, C Wiens, P Palacios, V Battaglia, M V Corna, R Sosa, R Gimenez, R Ruttia, E Szott, C Gonzales, C Godoy, A Acosta.

Peru: N Zavaleta, M Inga, D Galvez, B Cama, S Rico, C Tizón, T Jara, S Cabrera, J Silva, A Calero, O Chumbe, A Farro, S Palomino, A lyo, S García-Angulo,
A Vereau, R Ponce, B Paredes, R Villalta, O Requena, P Flores, F Sandoval, E Zapata; V Bazul, J Torres, R Chávez, J Arias, R Hinojosa, J Lị, P Wong, C Mendoza, R Rafael, J Ramirez, M Rivera, J Villar, T Hiromoto, C Puescas, M Vásquez, P Pacora, J Alva, E Llanos, R Lip, L Neciosup, B Liñán, R Chambi, M Sialer, M Huatuco; J Arango, L Hernández, G Rojas, J Rodríguez, E Aguirre, C Morales, V Chávez, R Gamarra, E Lazo, S Chávez, L Haro, A Gutiérrez, M P Quiróz, M E Arévalo, L Aquino.

Contributors: JV, GC, AF, AD, Leiv Bakketeig and AS were responsible for the idea and conception of the survey. JV, AS, GC, and AD prepared the protocol. LC, GC, JV, and AS supervised and coordinated the survey's overall execution in the Americas Region. DW, LC, JV, AD, DG, and MK were responsible for data management. DW, AD, and JV conducted the analysis. EV, NZ, AV, VB, AL, AN, MR, SR, KSdeP, and AA collaborated in the preparation of the protocol and the survey and implemented it in their respective countries; they actively contributed to the overall undertaking of the study. JV, GC, AD, DW, and AF wrote this paper with input from all the investigators. All the investigators read the report and made substantive suggestions on its content. JV is guarantor. Funding: UNDP/UNFPA/WHO/World Bank Special Programme of Research, Development and Research Training in Human Reproduction (HRP), Department of Reproductive Health and Research (RHR), WHO, and the US Agency for International Development (USAID)

Competing interests: None declared.

Ethical approval: The protocol was approved by the research ethics review committee of WHO and that of each participating country

Provenance and peer review: Not commissioned; externally peer reviewed.

1 Hamilton B, Minino A, Martin J, Kochanek K, Strobino D, Guyer B. Annual summary of vital statistics: 2005. Pediatrics 2007;119:345-60.

2 Althabe F, Belizan JM, Villar J, Alexander S, Bergel E, Ramos S, et al. Mandatory second opinion to reduce rates of unnecessary caesarean sections in Latin America: a cluster randomised controlled trial. Lancet 2004;363:1934-40.

3 Minkoff H, Powderly K, Chervenak F, McCullough L. Ethical dimensions of elective primary cesarean delivery. Obstet Gynecol 2004;103:387-92.

4 Kalish R, McCullough L, Gupta M, Thaler H, Chervenak F. Intrapartum elective cesarean delivery: a previously unrecognized clinical entity. Obstet Gynecol 2004;103:1137-41.

5 Villar I, Valladares E, Wojdyla D, Zabaleta N, Carroli G, Velazco A, et al. Caesarean delivery rates and pregnancy outcomes: the 2005 WHO global survey on maternal and perinatal health in Latin America. Lancet 2006;367:1819-29.

6 Department of Reproductive Health and Research. WHO global survey on maternal and perinatal health-project No A25176. Geneva: World Health Organization, 2004. www.medscinet.com/ who

7 Department of Reproductive Health and Research (RHR). WHO global survey on maternal and perinatal health-project No A25176. Operational manual. Geneva: World Health Organization, 2004.

8 Agresti A. Categorical data analysis. 2nd ed. New York: J Wiley, 2002.

9 Liang K, Zeger S. Longitudinal data analysis using generalized linear models. Biometrika 1986;73:13-22.

10 Chou YJ, Huang N, Lin IF, Deng CY, Tsai YW, Chen LS, et al. Do physicians and their relatives have a decreased rate of cesarean section? A 4-year population-based study in Taiwan. Birth 2006;33:195-202.

11 Declercq E, Barger M, Cabral H, Evans S, Kotelchuck M, Simon C, et al. Maternal outcomes associated with planned primary caesarean birth compared with planned vaginal birth. Obstet Gynecol 2007;109:669-77.

12 Hannah ME, Hannah WJ, Hewson SA, Hodnett ED, Saigal S, Willan AR. Planned caesarean section versus planned vaginal birth for breech presentation at term: a randomised multicentre trial. Lancet 2000;356:1375-83.

13 MacDorman MF, Declercq E, Menacker F, Malloy MH. Infant and neonatal mortality for primary cesarean and vaginal births to women with "no indicated risk", United States, 1998-2001 birth cohorts. Birth 2006;33:175-82.

14 Bloom S, Spong C, Thom E, Rouse D, Weininger S, Ramin S, et al. Fetal pulse oximetry and cesarean delivery. N Engl / Med 2006;355:2195-202.

15 Faas-Fehervary P, Schwarz K, Bauer L, Melchert F. Caesarean section on demand: influence of personal birth experience and working environment on attitude of German gynaecologists. Eur J Obstet Gynecol Reprod Biol 2005;122:162-6.

16 Fritel X, Ringa V, Varnoux N, Fauconnier A, Piault S, Bréart G. Mode of delivery and severe stress incontinence. A cross-sectional study among 2,625 perimenopausal women. BJOG 2005;112:1646-51. 
17 Buchsbaum G, Duecy E, Kerr L, Huang L, Guzick D. Urinary incontinence in nulliparous women and their parous sisters. Obstet Gynecol 2005;106:1253-8.

18 McKinnie V, Swift S, Wang W, Woodman P, O'Boyle A, Kahn M, et al. J. The effect of pregnancy and mode of delivery on the prevalence of urinary and fecal incontinence. Am J Obstet Gynecol 2005;193:512-7.

19 Emmett C, Shaw A, Montgomery A, Murphy D, on behalf of the DiAMOND study group. Women's experience of decision making about mode of delivery after a previous caesarean section: the role of health professionals and information about health risks. BJOG 2006;113:1438-45.
20 Moffat M, Bell J, Porter M, Lawton S, Hundley V, Danielian P, et al. Decision making about mode of delivery among pregnant women who have previously had a caesarean section: a qualitative study. BJOG 2007;114:86-93.

21 Lavender T, Kingdon C, Hart A, Gyte G, Gabbay M, Neilson J. Could a randomised trial answer the controversy relating to elective caesarean section? National survey of consultant obstetricians and heads of midwifery. BMJ 2005;331:490-1.

Accepted: 9 September 2007 